\title{
Whose Goals Count? Lessons for Setting the Next Development Goals
}

\section{Richard Manning, Charlotte Harland Scott and Lawrence Haddad}

\begin{abstract}
This IDS Bulletin brings together a set of articles about the lessons to be learned from the experience of the Millennium Development Goals, with a strong focus on Southern voices. The articles suggest that the MDG framework has had modest real world traction except where international aid has been significant. It has however successfully focused the global policy spotlight on some key development issues, and also improved the availability of data. But the Goals may have been too narrow, too often interpreted in silos, too much 'top-down', too little representative of the Millennium Declaration, and too little focused on the economic environment. A central message for those considering post-2015 frameworks is to ensure strong participation - 'nothing about us without us'. Many other specific suggestions are made for the overall structure and the key elements of an improved framework for international objective-setting after 2015.
\end{abstract}

As world leaders prepare for the special event on the Millennium Development Goals (MDGs) at the United Nations on 25 September, and as momentum builds in the debate about the case for Sustainable Development Goals beyond 2015, this IDS Bulletin draws together reflections from a range of Southern-based actors who between them have expertise on the various core elements of the MDGs and also on topics not explicitly covered in them, for example on governance, participation, and on infrastructure. We asked them to consider four specific questions, while also encouraging their broader thoughts. The questions were:

1 Has the MDG paradigm had any traction in your country/region?

2 If so, what changes has it encouraged, both positive and negative?

3 Would some kind of post-2015 framework be relevant and useful to your country/region?

4 If so, what key characteristics should it have?

We also include an article from a Northern-based expert on the links between the international development goal-setting experience and the increasing interest in better measurement of wellbeing in all countries.
We are extremely grateful to all those who have contributed, despite the pressures all were under. Our contributors include a serving President, a serving Minister, two Board members of IDS, and a wide range of academic and civil society representatives.

IDS has a particular stake in examining the effectiveness of the unique experiment in international goal-setting that the MDGs represent.

Sir Richard Jolly was a key advocate for targetsetting while Deputy Director of the United Nations Children's Fund (UNICEF) under Jim Grant. The UN Children's Summit of 1990 set new levels of ambition by putting in place seven 'Major Goals for Children and Development in the 1990s', six of them quantified, and no fewer than 26 supporting/sectoral goals in fields such as women's health and education, nutrition, child health, water and sanitation, and basic education. It was Richard Jolly again who encouraged the then Opposition Spokesperson on International Development, Clare Short, to make as a centrepiece of her work as Secretary of State the implementation of the International Development Goals agreed by the OECD Development Assistance Committee in 1996 (OECD 1996), themselves largely based on the 
various UN conferences that followed the Children's Summit.

It was IDS again which was tasked last year under the Participate initiative ${ }^{1}$ to bring perspectives of those in poverty into decisionmaking processes and ensure that marginalised people have a central role in holding decisionmakers to account in the post-2015 process. And the STEPS Centre ${ }^{2}$ at IDS has been closely involved in the UN process which is developing the Sustainable Development Goals approach following the Rio+20 conference in 2011.

The articles in this IDS Bulletin demonstrate the diversity of country and thematic responses to the unique experiment in international goalsetting that the MDGs represent, yet some common themes come through clearly. They are arranged as follows.

Adebayo Olukoshi, Rajesh Tandon and Mwangi Waituru reflect on issues around governance, accountability and the role of civil society and the poor themselves. Michael Kelly, Gita Sen and Anna Lartey consider these issues further with a focus on the social sectors, on gender and on nutrition. Sangui Wang, Mahendra Dev and Mthuli Ncube inject the economic dimension - the importance of agriculture, the problems of generating productive employment, the significance of infrastructure. Adnan Hezri considers the environmental aspects of sustainable development. Finally Enrico Giovannini draws together current thinking about how to measure the wellbeing of people and societies across the planet, and its relevance to the debate about a framework for agenda-setting after 2015.

\section{Have the MDGs had serious traction?}

It is clear that the traction of the MDGs has been very modest in countries like China, India and Malaysia. Sangui Wang observes that 'the MDGs needed China more than China needed the MDGs'. Rajesh Tandon notes the lack of any references to the MDGs in Indian Five-Year Plans (though also showing that India itself has a very similar approach to target-setting) and Adnan Hezri, while arguing that the MDGs were widely accepted by policymakers in Malaysia because they resonated well with its humanbased development philosophy, comments that the MDGs are seen by many countries as a UN agenda rather than as a national political priority. Indeed the consistent support by the United Nations Development Programme (UNDP) of the MDG paradigm, including periodic MDG assessments, has clearly been influential across the countries covered by our contributors. As Adebayo Olukoshi points out, 'For a majority of African countries, this task [MDG implementation] was carried out with active donor assistance and the technical superintendence of the UNDP which came to assume one of the most active roles in different countries as a central animator of the MDGs. Even civil society and parliamentary participation in local processes connected to the MDGs involved some degree of UNDP sponsorship and/or facilitation.'

The story in Africa appears distinctively different - up to a point. Here, the MDGs do appear to have been much more influential both with governments and with policy communities and civil society. President Joyce Banda makes this point powerfully: 'They have acted like a force, to push us. I don't remember any time in my 30 years working in the women's movement where we felt compelled to achieve [such results] because at the back of our minds, we know that New York is calling on us in 2015 to account.' Anna Lartey, writing from the viewpoint of nutrition, observes that 'The advent of the MDGs caused the searchlight to be focused on Africa' and that this was important in getting nutrition on the African Union (AU) agenda. Similarly Michael Kelly, reflecting on how Zambia was, like many other countries, already grappling with the issues to be covered by the MDGs, notes that 'The MDGs with their clear concern for human rights and human development provided a strong boost for what was already under way. They heightened the momentum and, because they were time-bound, increased the sense of urgency. Further, they established an environment that was highly conducive to more intense and purposeful action to reach very desirable but also highly elusive outcomes.'

However, although there appears to have been rather more direct reference to the MDGs in planning documents by African governments that was typically the case in middle-income countries elsewhere - in Kenya, for example, Mwangi Waituru reports that it is now government policy that in all the major undertakings of all ministries, at least two must be MDGs or core 
poverty related - it seems clear that, at least from the perspective of government, the MDGs have often been seen as very much an external and indeed donor-driven agenda. As Michael Kelly puts it, 'The goals, with their targets and indicators, were well accepted as a helpful guide to the direction in which the country's social sector should be moving. But it was a guide prepared outside Zambia without clear local participation in the specification of the individual goals or in the identification of targets and indicators.' And in Kenya, Mwangi Waituru observes that having come through a decade in which Kenya had struggled to provide basic services or to support development in the context of a bilateral aid freeze, massive indebtedness and the strictures of a full-scale structural adjustment programme, 'the government was highly likely to agree to any international development framework that brought with it the promise of development assistance. The MDGs, which appeared to be an agreement between donor and recipient countries, were thus timely and welcome. Having signed up to the MDGs, however, the government response reflected the notion that the framework was essentially topdown, with work towards the goals very much the agenda of the donors.'

Adebayo Olukoshi makes the thesis that while important governance implications flow in his view from the eight goals that were adopted, insufficient attention was paid to the critical importance of the context of participation and accountability, so that 'governance promises' turned into 'governance discontents'. This resonates with comments from several other contributors. Mwangi Waituru, for example, offers the perspective of a disillusioned senior Kenyan official who asked why African countries should pursue distractive global frameworks when they all had national development agendas to pursue - prompting some to complain that donors had not produced funds to support 'their' MDGs, and others to argue that Kenya had spent too much on reporting, monitoring and evaluation that had been required elsewhere.

From a civil society perspective, there were some more positive reactions. Adebayo Olukoshi observes that the MDGs as a globally adopted set of objectives fed into the long-standing quest in many countries where properly functioning social policy systems were not in place both for a prioritisation of social spending and the justiciability of core social and economic rights; and that the distinct elements of empowerment built into the MDGs appealed to a range of activist constituencies, especially those involved in the promotion of the rights of women and children, and the recognition of the critical relevance of civil society groups. He also comments that after the rigours of structural adjustment the campaigns for economic reform policies that did not target the social expenditure of the state for wholesale retrenchment found some resonance in the MDGs. However, as Adebayo observes, and as we shall see in the next section, this positive impact of the MDGs needs a good deal of qualification.

So - the MDG framework has had some real world traction in some circumstances, but little in others, with relative aid dependence (both of the country and of the specific MDG) maybe a marker of how significant this traction has been.

\section{What changes has the MDG framework encouraged, both positive and negative?}

Contributors tell a fairly consistent story about the positive and negative impacts of the MDGs, some of it deriving from the simple and actionable nature of the goals, which Mwangi Waituru suggests has been both the greatest strength of the MDGs - and also their greatest weakness.

On the positive side, contributors largely agree with Gita Sen's judgment that 'The MDGs successfully focused the global policy spotlight on some key development issues in the past decade.' President Banda singles out the value of the MDG framework in encouraging focus on specific and critical goals. Similarly, Anna Lartey reasons that they have helped lay the foundations for real progress in nutrition in Africa going forwards. Michael Kelly concludes that 'The MDG enterprise appears to have been unique in the way it focused world concern on the many dimensions of poverty experienced by more than a quarter of the human race. It was also distinctive in the simple but comprehensive and impressive road map it laid out for reducing the deprivations suffered by countless men, women and children. The whole undertaking also accomplished something very new and of boundless value in human experience - it united the whole of humanity in its aspiration towards development, towards improved prospects for all, and ultimately towards universal peace.' 
Enrico Giovannini introduces a different but significant positive aspect of the MDGs, noting that improvements in the reporting from countries to the international statistical system and increased access and understanding by agencies of existing national sources have led to a radical increase in knowledge of people's living conditions, with important implications for the accountability of governments. Strikingly, in just a decade, the percentage of countries and territories for which at least 16 of the MDGs indicators series are present at least two points in time rose from 2 to 83 per cent - a remarkable advance.

However, contributors devote a good deal more attention overall to the less positive aspects of the MDG experience. There are five main lines of criticism.

First, there is a concern, well expressed by Mthuli Ncube, that the MDGs focus too narrowly on social sectors, and that the requirements for the economic and environmental dimensions of sustainable development are neglected. This deserves a bit of unpacking.

Glearly some economic dimensions - income levels per head, productive employment, etc. are included (the latter however, as Mahendra Dev points out, some years after the original set). But several contributors consider that these aspects are not given sufficient focus. Mthuli Ncube feels that the MDGs de-emphasise the significance of the productive sectors, including infrastructure, and that they are therefore not encouraging structural transformation. Sangui Wang argues that broad-based rural income growth associated with market reforms and rapid economic development can explain most of the reductions in income poverty in China, not least in view of the relatively even distribution of land in the rural areas. (He also warns that as inequality has risen so rapidly in China, China is unlikely to achieve a similar rate of poverty reduction in future without the improvement of income distribution.)

Writing from a gender perspective, Gita Sen expresses concern that the MDGs never really tackled the larger macroeconomic and development framework within which policies or programmes for gender equality are located, or how conducive that framework is likely to be. She observes that the phenomenon of the working poor, or what Guy Standing terms the "precariat"3 (which may account in many developing countries for 80 per cent of women workers), has been growing in the last three decades of globalisation not only in developing but also in high-income countries, and has been exacerbated in the aftermath of the financial crisis of 2008. Mahendra Dev points out that as productivity has soared, elasticity of employment in the formal manufacturing sector in India has been declining in consecutive decades and that all the net increase in employment in the first decade of the century was in the 'unorganised' and 'informally organised' sectors, leading to a major dilemma over how to secure productive employment. The significance of these trends is huge and very concerning.

The environment is also of course mentioned in the MDG framework, but the relevant goal, targets and indicators are often, and with some justice, considered very inadequate. Adnan Hezri comments that unlike other established UN development goals such as health and education, MDG 7 is relatively 'ahistorical' and contains fewer concrete goals and indicators in comparison with the rest of the MDGs. He considers that the framing for environmental sustainability does not capture the complexity and breadth of the challenge. Only a small subset of issues is covered. For instance, the goal makes no reference to key environmental issues such as land degradation, population growth, and the eroding natural resource base so important for continuous human development in the developing world.

Even within the social sectors, there are wellknown problems, for example of having a target for access to primary education but with no target for educational achievement (interestingly a problem also with India's fifth Five-Year Plan set of targets quoted by Rajesh Tandon). Gita Sen similarly picks up the problems of the very limiting way that the target and indicators under MDG 3 were designed.

Secondly, several contributors are concerned that even though the MDGs might be seen as an attempt, however imperfect, to recognise key dimensions of wellbeing and multidimensional aspects of poverty, in practice they have been broken down into silos in a way that detracts from the holistic nature of the challenges that poor people face. 
Thus Gita Sen argues that the roots of deprivation and inequality lie in power relations that cut across multiple aspects of people's lives and are not specific to particular issues such as education or health or hunger. Instead she sees them as specific to particular groups of persons such as women and girls, and also groups disadvantaged or subordinated on other grounds.

In a similar vein, Michael Kelly feels that the way the goals were formulated may have encouraged them to be seen in isolation from one another, so that responsibility for their attainment was allocated to distinct silos, within separate ministries and government departments, but without sufficient appreciation that the MDGs constituted a unified holistic package. He suggests that it might have been better if the framework had more explicitly identified just two overarching goals - the eradication of poverty and the elimination of hunger - and then developed a set of subsidiary goals relevant to these.

Of course, it has always been open to people to take this more holistic approach. President Banda, for example, recognises explicitly that progress towards any of the MDGs in any case usually depends on a broad set of actions with positive results that go well beyond the MDG targets. In addressing women's empowerment, for example, she wants to see 'a village with water taps, a graded road, where inputs [are available] and crops are growing; where there is a market, a school and a clinic. To [achieve] one MDG, [a range of other priorities] also need to be addressed'. However, there seems little doubt that such broad thinking has not always been the norm, whether for governments, donors or advocates.

A third set of issues has to do with the top-down, 'made in New York' aspect of the MDG framework.

This perceived 'one-size-fits-all approach has at least two significant problems. First (whatever the intentions of its designers) it has come to be seen as setting a series of targets to be achieved at national level in every developing country. The effects of this can be problematic. President Banda gives the example of a school with 9,000 children, but only ten classrooms and 250 pupils per teacher. She comments that she has never seen children as they are now, where they can go through primary school and not be able to read.
Second, it has been seen as imposing targets that have not at all been the subject of discussion and buy-in from those affected. As Mwangi Waituru sees it, the goals are 'reductionist' and likely to distort development efforts, and lead to agendas that do not reflect national priorities. Further, numerical targets can create false incentives. As he goes on to say, 'As grass roots communities describe their lived realities, it is evident that what they envision is not necessarily what outsiders think they want. The strongest message from communities is a deep desire for the power to make decisions on issues that affect their lives; for access to equal opportunities; and for an enabling environment to sustain livelihoods.' Adebayo Olukoshi makes a very similar point, arguing that the architecture for the attainment of the goals has favoured a vertical accountability to the global at the expense of the local, a by-product of the attempt to transmit internationally determined targets into the local arena mainly on the basis of support from the donor community, from which has flowed what he terms a 'depoliticisation' of development experience, and the reduction of participation and accountability to a series of procedural technicalities. Michael Kelly gives a similar analysis from the perspective of Zambia.

Gita Sen likewise regrets the fact that the determination of goals, targets and indicators became in the main a technocratic exercise without adequate public debate or transparency especially to civil society. Consequently, short shrift was given to the human rights focused approaches that greater and more genuine participation and engagement of the people for whom the MDGs were intended would likely have prioritised.

\section{Fourth, some contributors feel that the MDGs} diluted the ambition and overarching vision of the Millennium Declaration. ${ }^{4}$ In doing so, Gita Sen repeats the argument that they 'dumbed down' the richer and more complete goals and targets of the UN Conferences of the 1990s, whose approaches were grounded in the lived realities of people's needs in different countries and regions.

Adebayo Olukoshi takes the view that on one of the issues covered in the Declaration but not the MDGs - that of governance - more progress would have been possible, since in his view 
important governance issues had to be addressed if progress was to be made on the goals. As he sees it, consistently with comments by Gita Sen and others picked out under the third set of issues above, insufficient attention was paid to the critical importance of the context of participation and accountability, and that this meant that the pursuit of the goals did not adequately feed into and/or add to the improvement of democratic governance, and, additionally, was frequently undermined by existing poor governance practices in Africa. In addition he argues that governments themselves usually chose to handle the MDGs through special units of one kind or another without adequately empowering relevant line ministries to get to work on them. This, as he sees it, reflected the impression that the goals were essentially an 'external' affair underwritten by donors - an impression further reinforced by the fact that parliaments felt themselves generally excluded from the MDGs.

Finally, some contributors emphasise the inadequate treatment of the wider macroeconomic framework within which the goals are to be addressed. As Gita Sen notes, Goal 8, which comes closest to this, though in a very loose manner, is the MDG that had the least in-built accountability for implementation. Adebayo Olukoshi, while noting that the MDGs were seen in many quarters as marking a move away from deflationary structural adjustment policies, lays emphasis on the need to ensure that macroeconomic policy is made to be compatible with broad social policy objectives.

\section{Would some kind of post-2015 framework be relevant and useful?}

Interestingly, few contributors chose to comment on this question, perhaps because, as Michael Kelly puts it, many actors are proceeding on the presumption that by the end of 2015 the UN will have established a new global framework for human development. This may, of course, be a premature assumption given the state of international debate on possible frameworks such as the Sustainable Development Goals and a more poverty-oriented framework.

Certainly much energy has gone into debating the nature of any such framework, including through the IDS Participate initiative, which brings together existing civil society movements with grass roots experience to ensure that their voices are heard. Encouragingly, Mwangi
Waituru, one of the contributors to Participate, says that the vision emerging from the UN and High-Level Panel work is quite similar to the evolving civil society vision for the post-2015 global development agenda: an equitable and sustainable world in which people have the 'power to make decisions that affect their lives, requires greater emphasis on building democratic governance and accountability; access to equal opportunities depends on addressing inequalities and exclusions across class, gender, religion, clan and other grounds of discrimination; [and] an enabling environment to sustain their livelihoods depends on inclusive and pro-poor economic development, underpinned by secure access to supportive and high quality services'.

Adebayo Olukoshi sees a place for global norms, standards, and targets; but reiterates that their domestication cannot, however, be undertaken on the basis of one-size-fits-all approaches.

Enrico Giovannini puts his comments in the context of the developing debate also in OECD countries about how to measure the progress of societies. As he points out, many individual attempts to find suitable metrics for this already exist, and the Stiglitz-Sen-Fitoussi Commission, established by President Sarkozy and which reported in 2009, presented an authoritative argument for a shift of emphasis from measuring economic production to measuring people's wellbeing. In line with its findings the European Union (EU) and several individual countries have done further work to measure wellbeing in various dimensions, and OECD itself now offers online data to which individuals can attach weights as they please. The European Commission has also set out in its Strategy for Smart, Sustainable and Inclusive Growth a series of MDG-like targets for 2020, including on employment, research and development, climate change, education and 20 million fewer people at risk of poverty; and Member States are to produce National Action Plans in support of these targets (European Commission 2010).

Enrico puts himself firmly in the camp of those arguing for universal goals, noting that every country is fighting against poverty, deprivation, social exclusion and to secure universal access to basic services, and that the effort for environmental sustainability needs to be a global and coordinated one. He argues that a 
multidimensional approach aimed at reaching equitable and sustainable wellbeing can

represent common ground for all countries which individual countries can then develop according to their specificities, capabilities and priorities.

Given this background, Enrico strongly welcomes the call from the Rio+20 conference for goals that would integrate the various dimensions of wellbeing, including its sustainability, without losing the 'unfinished business' of the Millennium Development Goals.

\section{What key characteristics should any new framework have?}

Naturally, contributors' views of this reflect their concerns about the aspects of the MDG framework criticised above.

\section{The strongest pleas have to do with effective} participation in any objective setting. As Anna Lartey puts it: 'It is not enough for global players to slap the developing world with development goals to be achieved in a specified timeline without giving directions and support on how these can be achieved and support to do that. In the global village we have created, achieving the MDGs is a concern for all - both developed and developing countries - and thus the post-2015 development goals should be an agenda for all.'

President Banda warns that this 'all-inclusiveness must happen all the way up to New York', and insists on the principle of 'nothing about us without us' and enabling people to be 'participating, not just as pictures, but real participation'. She adds, 'We don't want to get a feeling that some people will make our decisions for us, without asking what is it that we think will best work for us.'

Mwangi Waituru takes a similar view from a civil society perspective: 'Notwithstanding the significance of national and international processes, it is important to remember that the post-2015 framework is not for states, but for people. Outside government, the people of Kenya are asking how the new framework will influence the policies that affect their daily lives.' Adebayo Olukoshi urges that the existing social policies of the countries of Africa and the broader plans within which they are embedded should be used as the principal pillars around which global goals and targets are woven.
How to achieve this? Mwangi Waituru argues that the process through which new goals are framed should not mean simply engaging poor people in a consultation process - he wants the process of engagement to be part of a broader social movement. He argues that this requires a paradigm shift from a development approach to rights-based approach, with legally binding commitments. Gita Sen also argues for rightsfocused approaches that involve mechanisms of justiciability and accountability that can provide protection for the chronically poor and vulnerable 'precariat'. She observes that involving people directly in determining what will be done on their behalf will tend to make the choices more grounded and robust and programme implementation more effective. For women, this means not only their presence and participation but their voice and leadership.

Contributors have many thoughtful suggestions about both the content and the structure of a new framework. For example Mthuli Ncube argues that the post-2015 agenda must seek to promote African resilience by addressing associated vulnerabilities, including the effects of climate change. He suggests that the post-2015 framework should be framed around a few core objectives, aimed at solving a number of big global problems simultaneously. It might involve a combination of existing MDGs on development and poverty plus some other objectives around human rights, governance and wellbeing. Mahendra Dev observes that Indian thinking on development challenges appears to match with the global thinking on the Post-2015 Development Agenda with its latest Five-Year Plan calling for 'faster, sustainable and more inclusive growth', but he also argues for placing the employment issue at the centre of the national and international agenda. Rajesh Tandon, by contrast, focuses on issues of governance, which he sees as the fundamental problem in what he terms the 'complexity, contradiction and contestation' of India's development path - a path which has resulted in jobless growth, wider use of mobile phones than of toilets, and growing inequalities and regional disparities despite a tenfold increase in social sector development programmes over the past decade. His proposals for post-2015 goals include stretching targets for transparency, ease of doing business, reducing the black economy, increasing women's representation in the legislature, and administrative reform. 
Adnan Hezri calls for a post-2015 development framework that recognises that human development and a healthy planet can coexist, and for emphasising economic development rather than international aid. In terms of structure, he suggests tackling the dilemma between universal goals and highly dispersed national core or headline indicators by either using indicators harmonised at the international level or indicators selected by individual countries but falling under specific categories established by an international reporting agreement.

Michael Kelly opts for a not dissimilar approach, which reflects his view that development should be, as he puts it, both person-centred and universe-centred. The former implies robust measures to ensure that real expression is given to the unassailable dignity of every person; that determined efforts are made to bring about a more equitable distribution of the world's resources; and that every person is assured of access to life's necessities. The latter would recognise that we live in a universe characterised by interdependence and interconnectedness, not just between people but between people and everything that constitutes the natural environment in which they live. Hence, the Post2015 Development Agenda should vigorously address environmental preservation and, as a minimum, seek to contain and redress the ecological damage that the human family has already inflicted on it.

Enrico Giovannini is also focused on bringing out how sustainable development and societal progress may represent a common framework for all regions regardless of their level of income, model of consumption, social or political structure, or environmental challenges. $\mathrm{He}$ supports a multidimensional measure of wellbeing, using the concepts of equity and sustainability as two major crosscutting structural tools for analysis. He recognises however that while broad goals may be applied across all countries, targets and indicators will have to be customised to the positions of countries in different stages of development. He therefore proposes a mix of medium- to longterm goals and commitments by individual countries which would be both ambitious and feasible. (President Banda herself, in a rather similar vein, recommends that the post-2015 development framework articulates regional or perhaps continent-wide priorities and targets.) Enrico argues that the future model of development must be a common one for all regions of the world, and that in a globalised world all countries need to take their responsibilities. He points out that OEGD countries have major ones. On the one hand, they need to deliver on mobilising resources for development. On the other, the achievement of global Sustainable Development Goals is impossible without a change in the way people look at material consumption, climate change and transnational impacts of production, all topics where developed countries have major responsibilities.

Gita Sen notes that multiple sources of power inequality often intersect and reinforce each other as for example in India, where the intersecting oppressions of economic inequality, caste and gender, place poor Dalit women at the bottom of the social ordering, such that they are disadvantaged in relation to all of the MDGs. To address this while maintaining simplicity she suggests retaining broad and issue-focused goals, but setting the target derived from the goal in terms of specific group/s of people who are disadvantaged, subordinate, at risk or vulnerable. She sets out in her article the many advantages she sees from combining an issuefocused goal with people-focused targets. She goes on to argue that global criteria should be agreed for how to select target groups, but that decisions on which groups to target, based on these criteria, should be taken at national level.

While not everything in these prescriptions for the future match up with each other, and while large technical issues remain to be resolved, a clear vision emerges of goals, targets and indicators that respect local political processes, have much more ownership than the MDGs, pay attention to governance and accountability, build upon a framework of human rights, apply in some form to all countries, and aim to measure and so incentivise real progress in tackling poverty from a multidimensional perspective and building sustainability in all aspects of development and respect for the environment.

There is clear support for the High-Level Panel's emphasis on leaving no one behind, on sustainable development, and on transforming economies for jobs and inclusive growth. There is also clear 
support for its call to merge the social, economic and environmental dimensions of sustainability, hopefully facilitating a coherent outcome of the hitherto too separate discussions of poverty goals and Sustainable Development Goals. The Panel's proposal that each government could choose an appropriate level of ambition for each target, taking account of its starting point, its capacity and the resources it can expect to command, goes some way to address the concerns raised by contributors about local ownership, though it very much leaves open the role that actors other than governments could play in setting relevant

\section{Notes}

1 www.ids.ac.uk/participate.

2 http://steps-centre.org.

\section{References}

European Commission (2010) Europe 2020: A Strategy for Smart, Sustainable and Inclusive Growth, communication from the Commission, Brussels: European Commission

OECD (1996) Shaping the 21st Century: The

Contribution of Development Co-operation, Paris: objectives. Also the inclusion of clearer goals for employment, governance and energy (though transport remains a curious omission) resonate with many of the comments of contributors.

Most importantly, the open discussion of the value and contents of a new paradigm after 2015 represents a real advance from the situation in 2000-01, when the MDG framework was put in place behind closed doors. We hope that this IDS Bulletin will be a further contribution from IDS to an outcome that really will change people's lives sustainably for the better.

3 See Standing (2011).

4 www.un.org/millennium/declaration/ ares552e.htm

Organisation for Economic Co-operation and Development, www.oecd.org/dac/2508761.pdf (accessed 28 June 2013)

Standing, G. (2011) The Precariat - The New Dangerous Class, London: Bloomsbury Academic 